\title{
An Examination of Factors Affecting Fertility Rate Differentials as Compared Among Women in Less and More Developed Countries
}

\author{
Ashraf Ragab El-Ghannam \\ Senior Researcher, Department of Rural Sociology, Agricultural Extension \& Rural \\ Development Research Institute, Agriculture Research Center, Egypt
}

KEY WORDS Fertility Rate. Women’s Status. Development Level. Demographic Transition

\begin{abstract}
The fertility rate among the Less Developed Countries (LDC's) is at least triple as high as among the More Developed Countries (MDC's). The main objective of this study is to investigate the relationship between fertility rate differentials and child mortality, female life expectancy, age at the first marriage for women, Mean years of women education, and participation of women in labor force among LDC's and MDC's Countries. The study tries to determine empirically which of these factors are most significant in affecting fertility rate differentials. The interpretation of data is based on the demographic transition theory. The sample was involved 106 countries. According to World Bank report (1999), 53 of these countries are considering as LDC's, lowincome group, while others 53 are considering as MDC's, high-income group. The statistical methods used in this study are descriptive analysis, correlation coefficients, and multiple regression analysis. The results of descriptive analysis show that the mean of total fertility rate for LDC's was 6.1, while the mean in MDC's was 2.1. The results suggest that increase total fertility rate in LDC's are more occur among women who are have more children die, more number of years of life expectancy, more participate in labor force. $\mathrm{R}^{2}, .727$, regard to LDC's group explains $72.7 \%$ of the variance in total fertility rate. Moreover, the result implies that total fertility rate decrease among women's in MDC's that have more number of years of female life expectancy and more participation in labor force. The $\mathrm{R}^{2}$ for MDC's model was .590, meaning that the set of independent variables included in this equation explained $59.0 \%$ of the variance in total fertility rate.
\end{abstract}

\section{INTRODUCTION}

Fertility has strongly declined over the last three decades but a high fertility level persists in a part of the developing World. Disparities are therefore very pronounced. The causes of disparities and changes are diverse and complex. They are all linked to the development process. Recent availability of data for more than one hundred countries show that cross-country differences affect fertility rates significantly and this differences tend to diminish as countries become more developed.

The fertility rate among the Less Developed Countries (LDC's) is at least triple as high as among the More Developed Countries (MDC's). There are few variations between the MDC's, and total fertility rate implying from 1.2 to 3.7 live births per women. On the other hand, women in LDC's are expected to have from 3.5 to 6.9 children (PRB, 1999). Total fertility rates are comparative heterogeneity. This probably is a result of the beginning of local fertility declines in some LDC's as a new trend.

Address Correspondence to: Ashraf Ragab El-GhannamSenior Researcher, Department of Rural Sociology, Agricultural Extension \& Rural Development Research Institute, Agriculture Research Center, Egypt
According to Weeks (1994), high fertility in LDC's is explained by some theorists as a response to the pressures to have children created in high mortality societies by the need to replace members. Other pressures for children may be translated into a desire for children as security, labor, and desire for sons. In other LDC's, high fertility persists because so many people seem activity to desired large families.

Theories of low fertility in MDC's emphasize the role of wealth and economic development in lowering levels of fertility. Low fertility is typically explained as one strategy by which people seek to find wealth and prestige. In low fertility societies, higher strata's couples calculate more costs than benefits in having large families and thus decide to have fewer children than do as people in the lower strata's.

Although these reasons are clear in LDC's and MDC's, these are not some sufficient reasons for explain fertility differentials. There are some other factors affecting fertility differentials such as women's prestige, education, income, and other related factors often help to lower fertility. The main objective of this study is to investigate the relationship between fertility rate differentials and child mortality, female life expectancy, age at first marriage for women, Mean years of women education, and participation of women 
in labor force among in LDC's and MDC's Countries. The study will try to determine empirically which of these factors are most significant in affecting fertility rate differentials.

The study significance, This study deals with what happened in LDC's and MDC's regarding the total fertility rate. The study is significant because it is a global one. It included nine regions of the whole World compared to other studies that covered one or more regions.

\section{THEORETICAL FRAMEWORKS}

The interpretation of the data will be based on the demographic transition theory. According to Freedman (1979), the theory of the demographic transition is developed to explain the process by which the patterns characteristic of modern society emerged. The theory can be stated as follows: The immediate impact of modernization on promotes traditional societies is to improve food supplies, improve education and health. Birth rate remains at high levels, but death rates fall sharply, this produces the rapid population growth rates characteristic of the earliest stage of the transition. Most of the LDC's are in this high population growth stage. Moreover, traditional societies are generally characterized by high degree on reliance on family patterns of productions. Also, large families are given high value for both economic and status reasons.

Eventually, the socioeconomic changes brought by modernization emphasizes the importance of small families and birth rate will follow a declining pattern, which result in the declining population growth rates characteristic of MDC's (Macionis, 1991). The theory of the demographic transition is a perspective that emphasizes the important of economic and social development, which leads first to decline in mortality and then decline in fertility. It based on the experience of the MDC's.

In this study, fertility rate differentials examine the impact of economic and social development that characterized by women's status, such as women's education, life expectancy, and labor force. The basic assumption supporting the theory of fertility transition is that modernized societies will have lower fertility than traditional ones.

\section{LITERATURE REVIEW}

Over the past twenty years, there have been important changes in what women do. In LDC's women in urban areas made some significant improvement concerning health, economic, education, and social participation. While, there was little change in rural areas. The fertility rate declined somewhat, but still remains high. In MDC's, improvement in women's level of living increased steadily during the 1970s and 1980s. Fertility rate declined considerably and many inequalities in health, education, and employment were reducing in both urban and rural areas. Women's health is generally good and fertility rate is low. Although, fertility rates are declining in many LDC's, but the gap between LDC's and MDC's remains high. According to the United Nations (1995), in LDC's women have their first child at age 19 and the last child at age 37 . Compared with MDC's women have their first child at age 30 and the last child at age 37 .

Good health and family planning services are important for women and children in LDC's. Reduced infant mortality means that women can reach their desired family size with fewer pregnancies. There is a positive relationship between fertility and mortality. Parents do not know certainly how many of their children will die. The replacement may be greater than or less than the expected loss of children (Shullz, 1976).

Infant mortality can affect fertility through either a biological or a behavioral mechanism (Preston, 1975). The biological effect relates to the fact that women with early death will naturally resume ovulation earlier than women with surviving breasted children (Van Ginneken, 1974). The behavioral effect regards that couples with high infant mortality will seek to have additional children either to replace those that are lost, or as insurance against perceived potential losses (Preston, 1975).

The analysis of data of World Fertility Survey suggest that the declines in fertility and infant mortality among the population of Latin American countries that have been the last to become part of the demographic transition. Chackiel and Schkolnik (1997) conclude that future decreases in infant mortality, which is still high in Latin American countries, could 
consequently lead to further fertility declines. But a more significant change seems to depend upon the efficiency with which less educated women can narrow the gap between the number of children they wish to have and that which they actually do. In Sub-Saharan Africa, the findings from the Demographic and Health Surveys show that desired family size deceased significantly. Two third of the countries in this area have fertility decline with lower child mortality and higher education for women (Kirk and Pillet, 1998).

Child mortality appears to be on the rise in LDC's. According to Kane (1992), Some LDC's such as China, India, and Mali have infant mortality rate $30,95,167$ per 1,000 births, respectively. The lowest levels of infant mortality are in MDC's. For example, Japan, Sweden, Canada, and Netherlands have infant mortality rate about 4-7 per 1,000 births.

Women's life expectancy increased between 1970 and 1990 in every country. The increase for women averaged 8-9 years in MDC's and four years in the LDC's. In MDC's women can expect to live 75 years or more, while in LDC's, life expectancy is 45 years practically in Africa and western Asia (United Nations, 1995).

Women in LDC's marry when they are very young. The average age in these countries is below 20 years. While in MDC's the average is 23 years (United Nation, 1991). A woman's age at marriage is an important factor of her age when her first child is born. Many studies found strong negative correlation between age at marriage and fertility (Luker, 1975; Osterud and Fulton, 1976) particularly in Muslim countries (Karim, 1997). Osterud and Fulton (1976) in their study in Massachusetts found that the increase in age at first marriage from 1730 to 1850 causes a decrease in fertility.

There are large differences in overall women's literacy rates between LDC's and MDC's. According to United Nations (1995), in Latin America and some Asian countries the female enrollments in colleges and universities increase from 9 percent to 26 percent reflect investments in preparing women for new career opportunities. The woman's level of education affects fertility in many directions such as desire small family size because they prefer consumption items not related to children (Ranson, 1998; Rindfuss et al., 1999). Also, education increases women's income so they prefer to be in the labor force rather than take care of children (Graff, 1989). Education does not affect fertility directly, but it acts through many variables. The most important supply effects of education are age at marriage, infant and child mortality, and contraception use (Shapiro and Tambashe, 1997). Several studies confirmed the strong negative relationship between parents of education and their fertility behavior (Nouri, 1983; Graff, 1989; United Nations, 1991; and Lesthaeghe \& Willems, 1999).

Women's labor force participation rates have risen on 3.9 percent in the past 20 years, from 35.5 to 39.5 percent. Almost 80 percent of all employed women work including librarians, health technicians, secretaries, typists, teachers, and child care workers (Nielsen, 1990). McClamroch (1996) in his model of linear regression analyses suggests that the percentage of women in the labor force is directly related to total fertility rate, whereas the average number of years of education for women is indirectly related to total fertility rate.

The participation of women in managerial and administrative positions has doubled in MDC's from 14 percent in 1970 to 28 percent in 1990. Compared with LDC's, the participation is less than 10 percent. Nearly 50 to 80 percent of the economically active women still work in agriculture in Africa and Asia. In contrast, less than 5 percent of the economically active women in many European countries and United States works in agriculture (United Nations, 1998).

The participation of females in the labor force is negatively related to fertility rate for many reasons. Female employment outside the home is related to forming small families, working women tend to have fewer children than those who do not work because employment entails alternative satisfaction to children (Blake, 1979).

More studies was concerned on some areas in the World and concentrated on socio-economic factors as an impact of fertility. Panopoulou and Tsakloglou (1999) investigated the relationship between fertility and the number of socioeconomic factors among 13 developed and 55 developing countries. They found that there is a negative relationship between fertility and female education and a positive relationship between fertility and levels of infant mortality, whereas no significant relationship between fertility and 
female labor forces participation. Schkolnik and Chackiel (1998) in their study, on Latin America, note that, in many countries, women with the lowest levels of education have contributed to the reduction in the national levels of fertility. They found positive association between fertility and levels of infant mortality. In Sub-Saharan Africa, most of the recent data proved that there is negative association between age at marriage, number of year in school, and fertility, while there is positive association between infant and child mortality and fertility (Shapiro and Tambashe, 1999). Al-Qudsi (1998) demonstrates that age at marriage, women's education, women's labor, and infant mortality are important determinants of fertility in all Arab countries.

The literature review presented describes the variation of women's status in worldwide. Child mortality, female life expectancy, age at marriage for women, education for women, and women participation in labor force are variables selected for compare analysis in LDC's and MDC's Countries.

\section{METHODS}

Data and Sample: Data were collected from various sources. These include United Nations Statistical Yearbooks 2002, The World's Women: Trends and Statistics published by United Nations 2001, and Social Indicators of Development published by World Bank 2000. Selected variables from each of these sources were chosen to represent the dependent and independent variables for one year for this study.

The sample involved 106 countries. These countries divided by regions of World as a following. 21 from East and Southern Africa, 17 from West Africa, 10 from East Asia and Pacific, 6 from South Asia, 11 from Eastern Europe and Central Asia, 20 from Europe, 4 from Middle East, 3 from North America, and 14 from Latin America (Appendix A).

In the last report of the World Bank (2003), classified the countries by the income and region to three main groups. They consist of lowincome, middle income, and high-income group. The first group, low-income, of countries is considered as LDC's. The third group, highincome, of countries is considered as MDC's. In addition to, The United Nations Statistical
Yearbooks 1999 classified all the World countries by the total fertility and mortality rates to five groups. The majority of countries in first and second group are considered as LDC's and have high fertility rate. Also, The majority of countries in fourth and fifth group are considered as MDC's and have low fertility rate.

According to the World Bank Report (2003) and The United Nations Statistical Yearbooks 1999, the study employed the classifieds mentioned above to choose 53 of these countries as LDC's and another 53 countries as MDC's (Figs. 1 and 2).

Definition and Measurement of Variables: The following is a brief statement on the variables to be used and their measurement.

The Dependent Variable: Total fertility rate is defined as "the average number of children that would be born alive to a women during her lifetime if she were to pass through all her childbearing years conforming to the age specific fertility rates of a given year'. Total fertility rate measured by average number of children born per women during her lifetime.

Independent Variables: (1) Child mortality rate measured by children dying before reaching age five, per thousand live births. (2) Female life expectancy measured as a number of years may expect to live at time of birth. (3) Age at the first marriage of female measured as mean age at marriage of females that were never married. (4) Women's education measured as mean number of years of formal schooling that females have attained this for age 25 and order. (5) Women in labor force measured as percent of the total labor force in each country. Female life expectancy, age at marriage, women's education, and women in labor force were converted into a scale from 1 to 5 . The highest value is 5 and the lowest is 1 . Also, the child mortality rate was converted into a scale from 1 to 5, but the highest value is 1 and the lowest is 5 .

Statistical Methods: Descriptive analysis used to compare the average of the total fertility among and within LDC's and MDC's. Correlation coefficients will identify the relationship between the dependent and independent variables. Estimates of the amount of variance in total fertility rate that can be explained by each of the independent variables will be made using multiple regression analysis in LDC's and MDC's. 


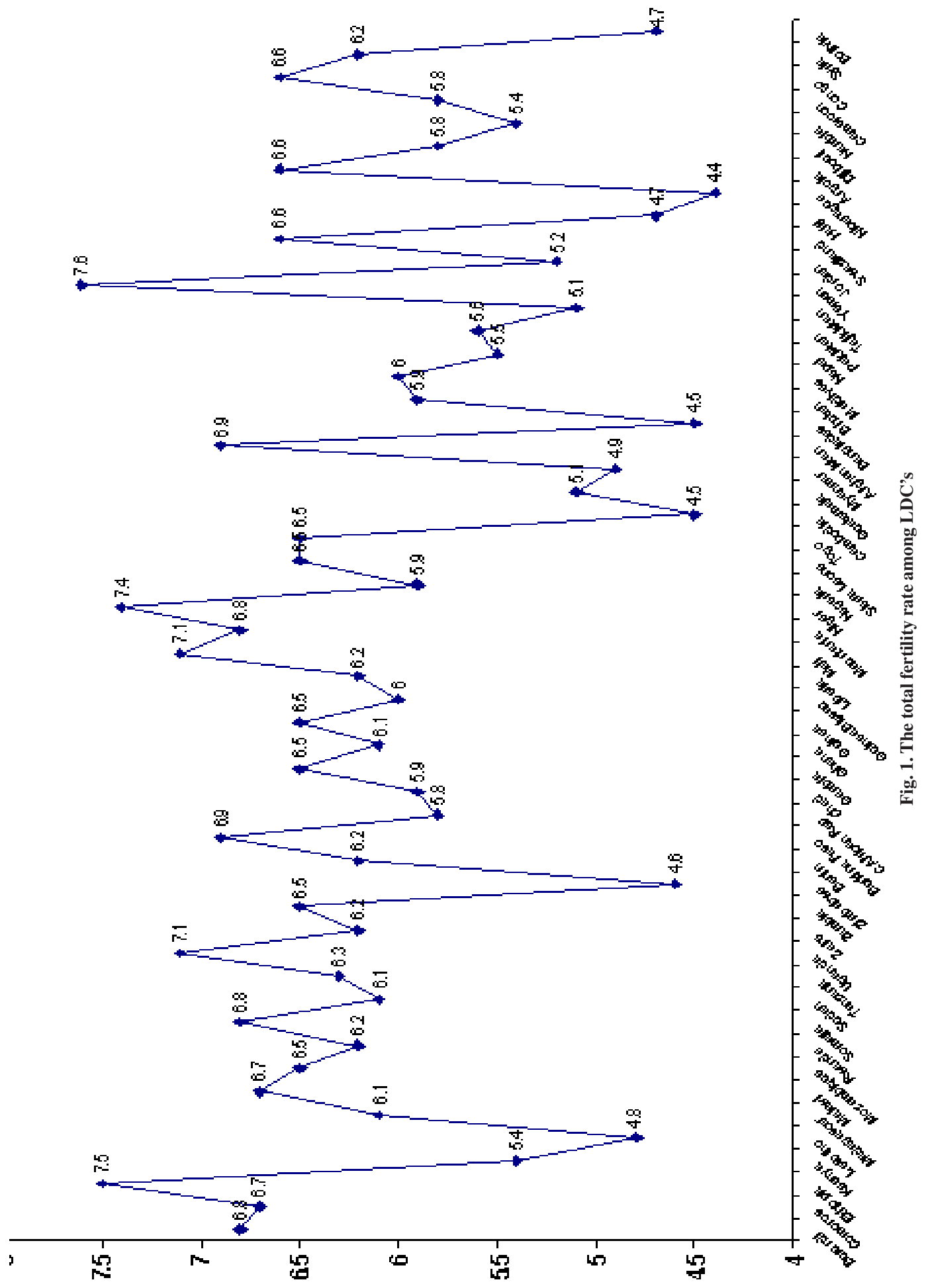




\section{RESULTS}

Results of Descriptive Analysis: Comparison between the average of the total fertility rate among and within LDC's and MDC's are presented in Table 1 and 2. The mean was used as a descriptive measure for all countries.

First, Less Developed Countries (LDC's): The highest mean of the total fertility rate was found in Yemen (7.6), Ethiopia (7.5), and Niger (7.4), while the smallest mean of the total fertility rate was found in Zimbabwe (4.6), Cambodia (4.5), Bangladesh (4.5), and Nicaragua (4.4). In the whole group of LDC's, the mean of the total fertility rate was found to be 6.1 child per women. The gap between the highest and smallest mean of the total fertility rate in this group was 3.2 (Yemen, 7.6, Nicaragua 4.4). The total fertility rate for $60 \%$ of LDC's was 6 and more, while $40 \%$ of LDC's was less than 6 (Fig. 1).

Second, More Developed Countries (MDC's): The highest total fertility rates were 4.1, 3.7, 3.6, and 3.5 for countries of South Africa, Kuwait, Venezuela, and Malaysia respectively, while the smallest total fertility rate were 1.2, 1.3, and 1.3 for countries of Spain, Germany, and Italy, respectively.

In the whole group of MDC's, the mean of the total fertility rate was found to be 2.1 child per women. The gap between the highest and smallest mean of the total fertility rate in this group was 2.9 (South Africa, 4.1, Spain 1.2). Related to the total fertility rate in this group, more than $65 \%$ of MDC's have average 2 or less, while less than $30 \%$ of MDC's have average of total fertility rate above 2. (Fig.2).

Related to both group of the countries, in all over the World, the highest mean of total fertility rate was found in Yemen (7.6), while the smallest mean of total fertility rate was found in Spain (1.2). There is large gap between total fertility rate in LDC's and MDC's, is estimated as four children per women. Although South Africa (4.1) and Nicaragua (4.4) were very close in the average of total fertility rate, but South Africa is classified as MDC's and Nicaragua is classified as LDC's, according to the World Bank Report (2003) and The United Nations Statistical Yearbooks 2002. (Fig 3. The total fertility rate among LDC's and MDC's).

Results of Correlation Coefficients: In this section correlation coefficients are presented. Table 3 shows the correlation among total fertility rate as dependent variables and child mortality rate, female life expectancy, age at marriage of female, women's education, and women in labor force as independent variables.

Regarding the LDC's group, it reveals a statistically significant positive association between total fertility rate and child mortality rate, $r=.265, p<.05$. Female life expectancy, $r$ $=-.802, \mathrm{p}<.001$, age at first marriage, $\mathrm{r}=-.562$, $\mathrm{p}<.001$, women's education, $\mathrm{r}=-.752, \mathrm{p}<.001$, and women in labor force, $r=-.273, p<.05$ have a statistically significant negative association with total fertility rate.

Related to the MDC's group, results in Table 3 indicate a statistically significant negative association between female life expectancy, $\mathrm{r}=$ $-.665, \mathrm{p}<.001$, age at first marriage, $\mathrm{r}=-.513$, $\mathrm{p}<.01$, women's education, $\mathrm{r}=-.654, \mathrm{p}<.001$, and women in labor force, $\mathrm{r}=-.669, \mathrm{p}<.001$.

These findings suggest that decrease total fertility rate in LDC's and MDC's is more likely

Table 1: The total fertility rate among less developed countries $(\mathbf{N}=\mathbf{5 3})$

\begin{tabular}{|c|c|c|c|c|c|c|c|}
\hline Countries & Mean & Countries & Mean & Countries & Mean & Countries & Mean \\
\hline Yemen & 7.6 & Congo & 6.6 & Sudan & 6.1 & Jordan & 5.2 \\
\hline Ethiopia & 7.5 & Mozambique & 6.5 & Ghana & 6.1 & Tajikistan & 5.1 \\
\hline Niger & 7.4 & Zambia & 6.5 & Guinea Bis. & 6 & Guatemala & 5.1 \\
\hline Uganda & 7.1 & Gambia & 6.5 & Maldives & 6 & Myanmar & 4.9 \\
\hline Mali & 7.1 & Guinea & 6.5 & Chad & 5.9 & Lesotho & 4.8 \\
\hline Burkina Faso & 6.9 & Sierra Leone & 6.5 & Nigeria & 5.9 & Haiti & 4.7 \\
\hline Afghanistan & 6.9 & Togo & 6.5 & Bhutan & 5.9 & Bolivia & 4.7 \\
\hline Burundi & 6.8 & Tanzania & 6.3 & Djibouti & 5.8 & Zimbabwe & 4.6 \\
\hline Somalia & 6.8 & Syria & 6.2 & Cameroon & 5.8 & Cambodia & 4.5 \\
\hline Mauritania & 6.8 & Rwanda & 6.2 & C. Africa R. & 5.8 & Bangladesh & 4.5 \\
\hline Comoros & 6.7 & Zaire & 6.2 & Pakistan & 5.6 & Nicaragua & 4.4 \\
\hline Malawi & 6.7 & Benin & 6.2 & Nepal & 5.5 & & \\
\hline Swaziland & 6.6 & Liberia & 6.2 & Kenya & 5.4 & Total & 320.2 \\
\hline Angola & 6.6 & Madagascar & 6.1 & Namibia & 5.4 & Mean & 6.05 \\
\hline
\end{tabular}




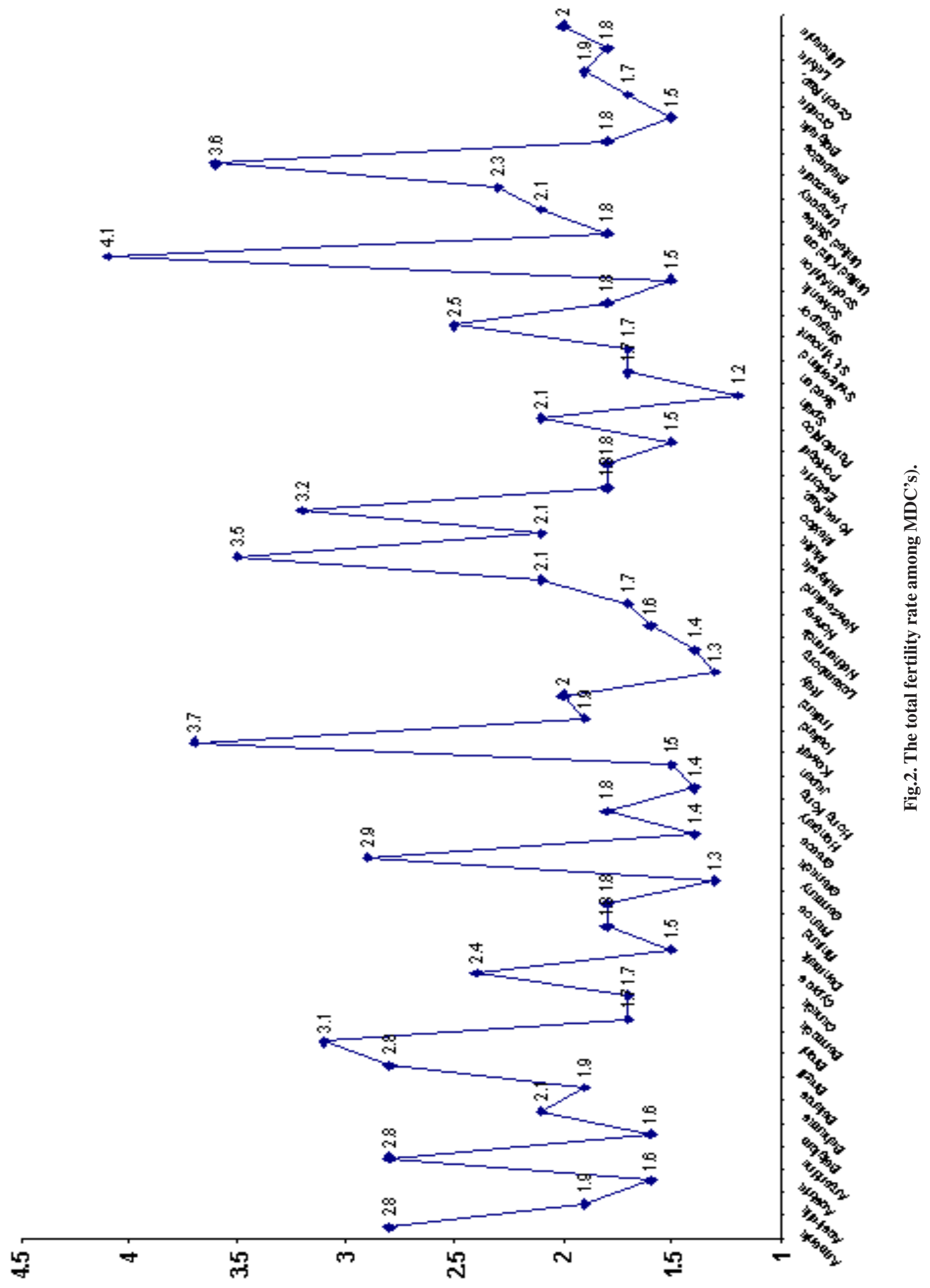


Table 2: The total fertility rate among more developed countries $(\mathrm{N}=53)$

\begin{tabular}{|c|c|c|c|c|c|c|c|}
\hline Countries & Mean & Countries & Mean & Countries & Mean & Countries & Mean \\
\hline Spain & 1.2 & Bermuda & 1.7 & Latvia & 1.8 & St. Vincent & 2.5 \\
\hline Germany & 1.3 & Canada & 1.7 & Australia & 1.9 & Armenia & 2.8 \\
\hline Italy & 1.3 & Norway & 1.7 & Belarus & 1.9 & Argentina & 2.8 \\
\hline Greece & 1.4 & Sweden & 1.7 & Czech Rep. & 1.9 & Brazil & 2.8 \\
\hline Hong Kong & 1.4 & Switzerland & 1.7 & Iceland & 1.9 & Grenada & 2.9 \\
\hline Luxembourg & 1.4 & Croatia & 1.7 & Ireland & 2 & Brunei & 3.1 \\
\hline Denmark & 1.5 & Barbados & 1.8 & Lithuania & 2 & Mexico & 3.2 \\
\hline Portugal & 1.5 & U. Kingdom & 1.8 & Bahamas & 2.1 & Malaysia & 3.5 \\
\hline Japan & 1.5 & Finland & 1.8 & New Zealand & 2.1 & Venezuela & 3.6 \\
\hline Slovenia & 1.5 & France & 1.8 & Malta & 2.1 & Kuwait & 3.7 \\
\hline Bulgaria & 1.5 & Korea Rep. & 1.8 & Puerto Rico & 2.1 & South Africa & 4.1 \\
\hline Austria & 1.6 & Estonia & 1.8 & U.States & 2.1 & & \\
\hline Belgium & 1.6 & Hungary & 1.8 & Uruguay & 2.3 & Total & 108.5 \\
\hline Netherlands & 1.6 & Singapore & 1.8 & Cyprus & 2.4 & Mean & 2.05 \\
\hline
\end{tabular}

to occur among women who are have more number of years of life expectancy, marry in adequate age not early, more educated, and involved in labor force. Results also show that correlation support one of the most important variable affecting total fertility rate in group of LDC's, it is child mortality rate. Total fertility rate increases with the increase of child mortality rate. This was only different between each group of countries.

Results of Multiple Regression: This section presents the results of the multiple regression analysis. It is used to estimate the effects of a set of independent variables on the dependent variables included in this study.

First, the results of multiple regression for LDC' group in Table 4 displays that the standardized regression coefficient for child mortality rate, .163, female life expectancy, .555 , and women in labor force, -.226 , were statistically significant at level .05, .001, and .01, respectively. The results indicate that these variables were the best predictors of the total fertility rate in LDC's. The results suggest that increase total fertility rate in LDC's occur more among women who are have more children die. Moreover, total fertility rate decreases with the increased in the number of years for female life expectancy, and among women who can participate in labor force. The other variables were not statistically significant. $\mathrm{R}^{2}, .727$, regard to LDC's group explains 72.7 percent of the variance in total fertility rate.

Second, the results of the multiple regression of total fertility rate in MDC's are presented in Table 4 . The standardized regression coefficient for female life expectancy, -.291, and women in
Table 3: Correlation coefficients among indepen-dent and dependent variables in LDC'S and MDC'S

\begin{tabular}{lcc}
\hline $\begin{array}{l}\text { Independent } \\
\text { variables }\end{array}$ & \multicolumn{2}{c}{$\begin{array}{c}\text { Dependent Variable (Total } \\
\text { fertility rate) }\end{array}$} \\
\cline { 2 - 3 } & $\begin{array}{c}\text { LDC's } \\
(N=53)\end{array}$ & $\begin{array}{c}M D C \text { 's } \\
(N=53)\end{array}$ \\
\hline 1- Child Mortality Rate & $.265 *$ & .159 \\
2- Female Life Expectancy & $-.802 * * *$ & $-.665 * * *$ \\
3- Age at First Marriage & $-.562 * * *$ & $-.513 * *$ \\
4- Women's Education & $-.752 * * *$ & $-.654 * * *$ \\
5- Women in Labor Force & $-.273 *$ & $-.669 * * *$ \\
\hline$* \mathrm{p}<.05, * * \mathrm{p}<.01, * * * \mathrm{p}<.001$ & & \\
\hline
\end{tabular}

labor force, -.360, were negative statistically significant at level .05 . This result implies that total fertility rate decreases among women in MDC's that have more number of years of female life expectancy and more percent of women participation in labor force. The other remaining variables were not statistically significant. The $\mathrm{R}^{2}$ for MDC's model was .590, meaning that the set of independent variables included in this equation explained 59.0 percent of the variance in total fertility rate.

\section{DISCUSSION}

There is still much work to be done to improve women's status. Despite advances in health, education and working conditions, life for millions of women remains needlessly hard in all over the world. The results of this study and previous study suggest that only if women's works outside the home will she be amenable to be low fertility pressures. Women's involvement in the labor force has increased during the 1980 s 


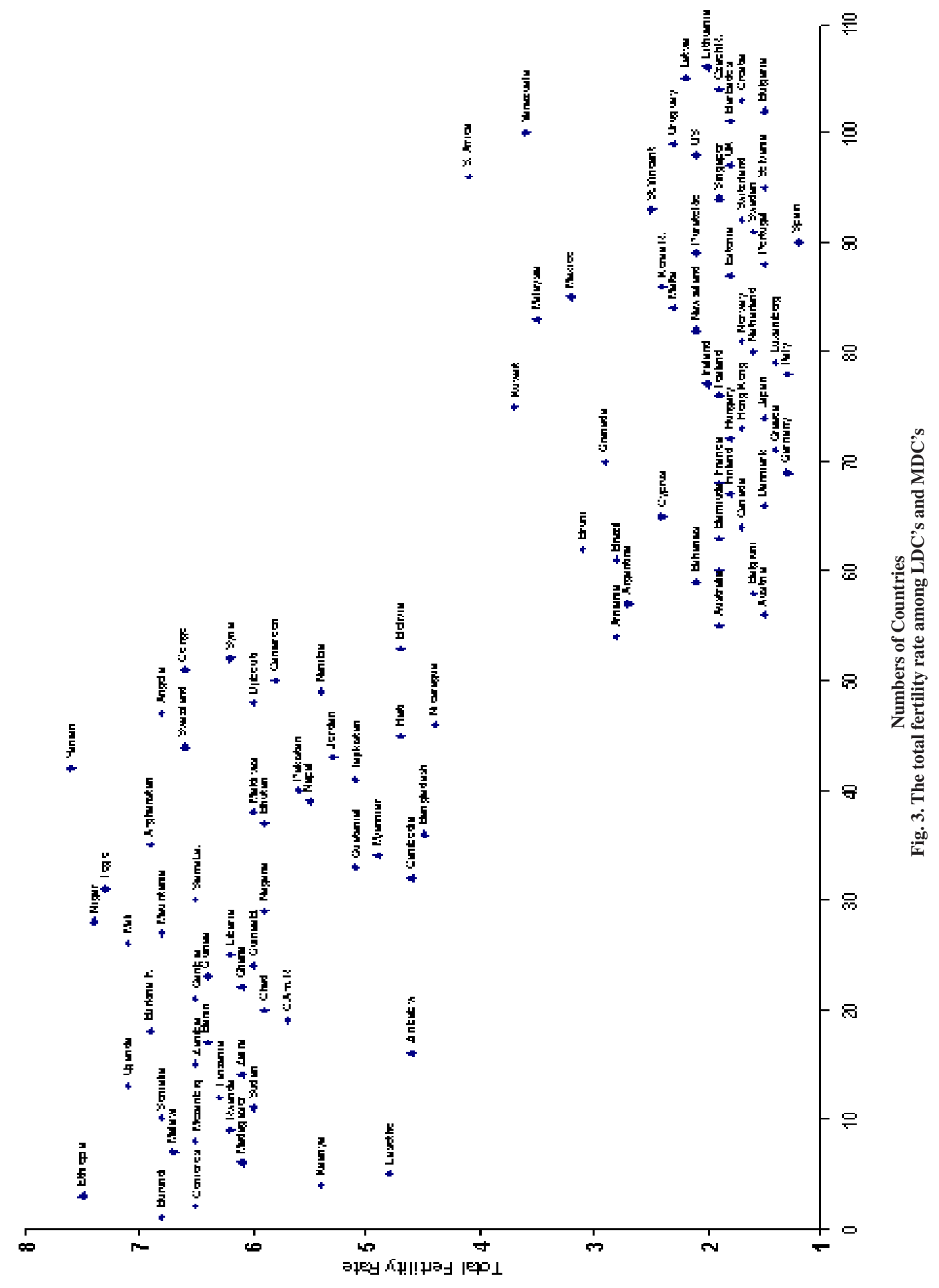


and 1990s, especially in the LDC's, as economic crises and reduces employment opportunities. The need for an additional source of family income remains great. The women can make this role by participation in labor force. People in LDC's should change attitudes of employers toward women. Governments should ensure full participation of women in economic, social, political life, and as same as labor force.

Women in some LDC's have an average of less than a year's formal education. In contrast, women in MDC's usually finish high school and many proceed on to higher education at the university level. Formal education provides

Table 4: Multiple regression of the total fertility rate in LDC'S and MDC'S

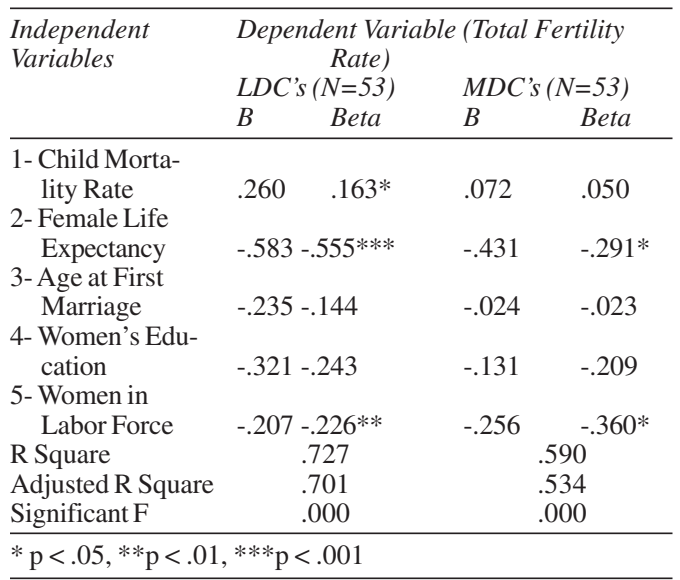

women access resources and power, particularly with respect to employment in the labor force. With more women completing the university degree, the numbers of women becoming economically active in the labor force. The age of the first marriage contributes to a lowering of the total fertility rate and makes it more feasible for women to join the labor force and be economically better off.

Life expectancy varies by level of development in all countries. According to the United Nations reports (2001), the average life expectancy was 74.5 years in MDC's and 51.0 years in LDC's. A significant relationship between life expectancy and total fertility rate indicates the negative association. Related to this result, women life expectancies increase, the fertility rate decrease. Expectation of women life should exceed to 74 years in 2000 as suggestion by World Population Conference. This give causes for concern social welfare and improve quality of life in LDC's.

In LDC's, child mortality is quite high in hose countries that fall into the poor and extremely poor health and education. Therefore, the total fertility rate can be more than eight in some LDC's. There is a big difference between the LDC's and MDC's in what speeded the drop in child mortality rate. The LDC's should make some efforts to transfer public health knowledge and medical technology from the MDC's. Much of this had taken place, although there is considerable unevenness in the pattern of child mortality rate decline throughout the LDC's areas. Highest priority should be given to the reduction of high child mortality rate. Among LDC's, child mortality tended to be lowest in Latin their political, social, economic, education, and health status are essential to each country's America, followed by Asia, most African nations trailing behind in terms of their success at battling disease.

According to the U. N. Conference on Population and Development held in Cairo, Egypt (1994), the empowerment and autonomy of women and improvement of achievement of sustainable development (United Nations, 1994). Moreover, at the first intergovernmental global population conference at Bucharest in 1974, Thomas and Price (1999) argued that rapid population growth would only be controlled when a more equitable relationship was established between the More and Less Developed Countries, leading to accelerated social and economic development in the future. Over the subsequent quarter of a century this perspective has been progressively displaced as the dominant paradigm by the view that sustained fertility decline can be accomplished through good quality family planning programs in the context of gender-sensitive social policies, including formal education.

In sum, raising both of women life expectancy and women participation in labor force appear to be the most important means of lowering total fertility rate of women in LDC's and MDC's. Other contributing factors include; such as adequate age at first marriage, raising educational attainment, and improvement health care of women that reduce child mortality rate. These factors support lowering total fertility rate of women in LDC's. 


\section{REFERENCES}

Al-Qudsi, S. S. : Labor Participation of Arab Women: Estimates of the Fertility To Labor Supply Link. Applied Economics, 30(7): 931-941 (1998). London, England.

Blake, J.: Is Zero Preferred: American Attitudes toward Childlessness in the 1979's. Journal of Marriage and the Family, 4: 245-257 (1979).

Chackiel, Juan and Schkolnik, Susana: Latin America: Less Advanced Groups in Demographic Transition. International Union for the Scientific Study of Population. Belgium, 1: 249-267 (1997).

Freedman, Ronald: Theories of Fertility Decline: A Reappraisal. Social Forces, 8(1): 1-17 (1979).

Graff, H.. Literacy, Education, and Fertility Past and Present: A Critical Review. Population and Development Review, 5(1): 33-54 (1979).

Kane, Hal: Infant Mortality Declining. In Vital Signs, Lester R. Brown, Christopher F. and Hal Kane (Eds.) Washington, D.C.: Worldwatch Institute (1992).

Karim, Mehtab: Reproductive Behavior in Muslim Countries. Working Paper, No. 23, Oct. 1997. Macro International Demographic and Health Survey (DHS): Calverton, Maryland. USA (1997).

Kirk, Dudley and Pillet, Bernard: Fertility Levels, Trends, and Differentials in Sub-Saharan Africa in the 1980s and 1990s. Studies in Family Planning, 29(1): 1-22. NY, USA (1998).

Lesthaeghe, Ron and Willems, Paul: Is Low Fertility A Temporary Phenomenon in the European Union? Population and Development Review, 25(2): 211-228. NY, USA (1999).

Luker, K.: Taking Chances: Abortion and the Decision not to Contraceptive. Berkeley: University of California Press (1975).

Macionis, J. J.: Sociology. 3rd edition, Englewood Cliffs, New Jersey (1991).

McClamroch, Kristi: Total Fertility Rate, Women's Education, and Women's Work: What are the Relationships? Population and Environ-ment, 18(2): 175-186. NY, USA (1996).

Nielsen, J. M.: Interpreting Gender. In Signs: Journal of Women in Culture \& Society, 7: 15-26. Chicago: University of Chicago Press (1990).

Nouri, O. M.. Fertility Differentials in the Sudan. Ph.D. Thesis (Unpublished), Department of Sociology, Mississippi State University, Mississippi State, USA (1983).

Osterud, N. and J. Fulton: Family Limitation and Age at Marriage: Fertility Decline in Sturbridge, Massachusetts, 1730-1850. Pop-ulation Studies, 30: 481-492 (1976).

Panopoulou, Gito and Tsakloglou, Panos: Fertility and Economic Development: Theoretical Considerations and Cross-Country Evidence. Applied Economics, 31(11):1337-1352. London, England. (1999).

Population Reference Bureau. 1999. World Propulation Data Sheet Prestion Growth. Population and Development Review. 1:189-200, (1999).

Ranson, Gillian. Education, Work and Family Decision Making: Finding the Right Time To Have A Baby. Canadian Review of Sociology and Anthropology, (35)4: 517-533. Montreal, Canada (1998).

Rindfuss, R. R.; Brewster, K. L.; and Kavee, A. L.: Women, Work, and Children: Behavioral and Ideational Change in the US. In: Dynamics of Values in Fertility Change, Clarendon Press: Oxford, England (1999).
Schkolnik, Susan and Chackiel, Juan: Latin America: Demographic Transition in Less Developed Sectors, Population Studies, (26)6: 7-53 (1998).

Shapiro, David and Tambashe, B. O.: Education, Employment, and Fertility in Kinshasa and Prospects for Changes in Reproductive Behavior. Population Research and Policy Review, (16)3: 259-287, Dordrecht, Netherlands (1997).

Shapiro, Davie and Tambashe, B. O.: Fertility Transition in Urban and Rural Areas of Sub-Saharan Africa. Population Research Institute, Working Paper, No. 99-12: 1-19. Pennsylvania State University, Population Research Institute: University park, Pennsylvania, USA (1999).

Shultz, T. P.: The Value of Children: An Economic Perspective. Journal of Political Economy, 81(2): Pp: 513-520 (1976).

Starke, Linda: Fertility Rate Decline Stalls. in Vital Signs 1993, Lester R. and Hal Kane (eds.). Washington, D. C.: Worldwatch Institute (1993).

Thomas, Neil and Price, Neil: The Role of Development in Global Fertility Decline. Futures, 31(8): 779-802. Oxford, England.(1999).

United Nations: Women: Challenge to the Year 2000. New York, USA (1995).

United Nations: Women: Trend and Statistics 1970-1990. New York, USA (2001).

United Nations: Statistical Yearbooks, United Nations (2002).

United Nations: Human Development Report, United Nations Development Program. Oxford University Press (1997).

United Nations Conference for Population: Report of population and Development, 5-3 September, Cairo, Egypt (1994).

Van Ginneken, J. K.. Prolonged Breast-feeding As A Birth Spacing Method. Studies in Family Planning, 5: 177206, (1974).

Weeks, R. John. Population: An Introduction to Concepts and Issues. Wadasworth Publishing Company, Belmont, California (1994)

World Bank: Social Indicators of Development, Published by World Bank. The Johns Hopkins University Press. Baltimore and London (2000).

World Bank: World Bank Report. , Published by World Bank, The Johns Hopkins University Press. Baltimore and London (2003).

\section{APPENDIX CLASSIFICATION OF COUNTRIES BY REGIONS}

East and Southern Africa (21 Countries): Less Developed Countries (20 Countries): Angola, Burundi, Comoros, Djibouti, Ethiopia, Kenya, Lesotho, Madagascar, Malawi, Mozambique, Namibia, Rwanda, Somalia, Sudan, Swaziland, Tanzania, Uganda, Zaire, Zambia, and Zimbabwe. More Developed Countries (1 Country): South Africa.

West Africa (17 Countries): Less Developed Countries (17 Countries): Benin, Burkina Faso, Cameroon, Central African Rep., Congo, Chad, Gambia, Ghana, Guinea, Guinea Bissau, Liberia, Mali, Mauritania, Niger, Nigeria, Sierra Leone, and, Togo.

East Asia and Pacific (10 Countries): Less Developed Countries (2 Countries): Cambodia, Myanmar More Developed Countries (8 Countries): Korea Rep., Malaysia, Australia, Japan, New Zealand, Brunei, Hong Kong, and 
Singapore.

South Asia (6 Countries): Less Developed Countries (6

Countries): Afghanistan, Bangladesh, Bhutan, Maldives, Nepal, and Pakistan.

Eastern Europe and Central Asia (11 Countries): Less Developed Countries (1 Country): Tajikistan, More Developed Countries (10 Countries): Armenia, Belarus, Bulgaria, Croatia, Czech Rep., Estonia, Hungary, Lithuania, Latvia, and Slovenia.

Rest of Europe (20 Countries): More Developed Countries (20 Countries): Austria, Belgium, Cyprus, Denmark, Finland, France, Germany, Greece, Iceland, Ireland, Italy,
Luxembourg, Netherlands, Norway, Malta, Portugal, Spain, Sweden, Switzerland, and United Kingdom.

Middle East (4 Countries): Less Developed Countries (3 Countries): Syria, Jordan, and Yemen. More Developed Countries (1 Country): Kuwait.

North America (3 Countries): More Developed Countries (3 Countries): Canada, Mexico, and United States.

Latin America (14 Countries): Less Developed Countries (4 countries): Bolivia, Guatemala, Haiti, and Nicaragua. More Developed Countries (10 countries): Argentina, Bahamas, Barbados, Bermuda, Brazil, Grenada, Puerto Rico, St. Vincent, Venezuela, and Uruguay. 